\title{
Neonatal Neutropenia
}

National Cancer Institute

\section{Source}

National Cancer Institute. Neonatal Neutropenia. NCI Thesaurus. Code C111855.

A condition characterized by a decrease in the number of neutrophils in the blood below established reference ranges in a newborn. 